\title{
BMJ Open Child maltreatment as a predictor of adult physical functioning in a prospective British birth cohort
}

\author{
Gemma Archer, Snehal Pinto Pereira, Christine Power
}

\begin{abstract}
To cite: Archer G, Pinto Pereira S, Power C. Child maltreatment as a predictor of adult physical functioning in a prospective British birth cohort. BMJ Open 2017;7:e017900. doi:10.1136/ bmjopen-2017-017900

- Prepublication history and additional material for this paper are available online. To view these files, please visit the journal online (http://dx.doi. org/10.1136/bmjopen-2017017900).
\end{abstract}

Received 23 May 2017 Revised 5 September 2017 Accepted 28 September 2017

CrossMark

Population, Policy and Practice, UCL Great Ormond Street Institute of Child Health, University College London, London, UK

Correspondence to Professor Christine Power; christine.power@ucl.ac.uk

\begin{abstract}
Objective Child maltreatment (abuse and neglect) has established associations with mental health; however, little is known about its relationship with physical functioning. Physical functioning (ie, the ability to perform the physical tasks of daily living) in adulthood is an important outcome to consider, as it is strongly associated with an individual's ability to work, and future disability and dependency. We aimed to establish whether maltreatment was associated with physical functioning, independent of other early-life factors.
\end{abstract}

Setting 1958 British birth cohort.

Participants 8150 males and females with data on abuse and who participated at age 50 years.

Outcome measures The primary outcome was poor physical functioning at 50 years $(\leq 65$ on the Short-Form 36 survey physical functioning subscale). Secondary outcomes included mental health and self-reported health at 50 years.

Results $23 \%$ of participants reported at least one type of maltreatment; $12 \%$ were identified with poor physical functioning. Neglect $\left(\mathrm{OR}_{\mathrm{adj}} 1.55,95 \% \mathrm{Cl} 1.24\right.$ to 1.93$)$, psychological abuse $\left(\mathrm{OR}_{\mathrm{adj}}^{\mathrm{adj}} 1.49,1.17-1.88\right)$ and sexual abuse $\left(0 \mathrm{R}_{\mathrm{adj}} 2.56,1.66-3.96\right)$ were associated with poor physical functioning independent of other maltreatments and covariates, including childhood social class, birth weight and childhood illness. Odds of poor physical functioning increased with multiple types of maltreatment $\left(\mathrm{p}_{\text {trend }}<0.001\right) ; 0 \mathrm{R}_{\text {adj }}$ ranged from $1.49(1.23-1.82)$ for a single type to 2.09 (1.53-2.87) for those reporting $\geq 3$ types of maltreatment, compared with those with none. Associations of similar magnitude were observed for mental and self-reported health outcomes.

Conclusions Child neglect, psychological and sexual abuse were associated with poor physical functioning at 50 years, with accumulating risk for those with multiple types of maltreatment. Associations were independent of numerous early-life factors and were comparable in magnitude to those observed for mental health and selfrated health. Prevention or alleviation of the ill effects of maltreatment could be an effective policy intervention to promote healthy ageing.

\section{INTRODUCTION}

A rapidly ageing population in Western countries coupled with escalating health and social care costs has led to an urgent need to reduce ill health and disability in later life. ${ }^{1}$ Physical

\section{Strengths and limitations of this study:}

Data were from a large population-based cohort followed from birth to age 50 years, which allowed prospective ascertainment of childhood neglect, early-life covariates and adult outcomes.

- Childhood abuse was obtained retrospectively, but 5 years prior to outcome ascertainment, reducing the possibility of recall bias.

- Sample reductions due to missing data were addressed using multiple imputation.

functioning (ie, the ability to perform the physical tasks of daily living) is strongly associated with future disability, in addition to other important outcomes including hospitalisations, falls, nursing home admissions, higher levels of dependency and mortality. ${ }^{2-4}$ It is therefore important to understand the determinants of physical functioning and in order to plan effective points of policy intervention, necessary to understand proximal and distal determinants. There is growing evidence that early-life conditions such as socioeconomic position, ${ }^{5}$ birth weight ${ }^{6}$ and parental health ${ }^{7}$ are associated with physical functioning in adulthood, but little is known about the specific influence of child maltreatment (including abuse and neglect) as relatively few studies have been undertaken. Child maltreatment may be an important early-life influence on adult physical functioning as it is associated with long-term morbidity and poor socioeconomic outcomes, including low educational attainment, ${ }^{8}$ less upward social mobility, ${ }^{9}$ mental health problems, unhealthy behaviours and chronic diseases, ${ }^{810}$ which in turn are associated with subsequent physical functioning. ${ }^{41-15}$ Evidence on the potential role of child maltreatment is of particular interest because it is not uncommon; in the UK, an estimated $22 \%$ of those under 17 report having experienced $\geq 1$ form of maltreatment, ${ }^{16}$ with equally high levels reported in the USA and Europe. ${ }^{8}$ 
Existing studies examining associations between child maltreatment and physical functioning in adulthood have relied on cross-sectional samples from USA, ${ }^{17-21}$ were limited to women ${ }^{19-21}$ or examined sexual abuse only. ${ }^{21}$ Few studies have examined neglect, and of those which have, maltreatments were combined so differential effects could not be identified. ${ }^{19}{ }^{20}$ Previous work has also combined wide age groups, ${ }^{17-21}$ which can lead to biased estimates, ${ }^{22}$ and because studies have accounted for limited ${ }^{19}$ or no ${ }^{17182021}$ early-life confounders, it is unclear whether observed associations are distinct from other childhood factors known to be associated with adult physical functioning. Furthermore, few studies consider the role of potential intermediary factors such as adult mental health or socioeconomic position, in any maltreatment-physical functioning associations. Such gaps in knowledge also apply to other markers of disadvantaged childhood environment such as socioeconomic position $^{5}$; while the latter is associated with several factors (eg, growth and nutrition) that affect peak physical fitness and capability achieved by early adulthood, the extent to which child socioeconomic position-adult physical functioning associations reflect an influence of maltreatment is unclear.

Therefore, using longitudinal data from a large British birth cohort followed to 50 years, we aimed to establish whether child maltreatment was associated with later physical functioning and to assess whether this association was independent of other early-life factors. International standards for defining physical functioning and disability and links between these concepts have been developed in the WHO's 'International Classification of Impairments, Disabilities and Handicaps' recently revised as the International Classification of Functioning, disability and health (ICF) ${ }^{23}$ While the ICF provides a comprehensive framework, it has been suggested that the physical functioning subscale of the Short-Form 36 (SF-36) ${ }^{24-26}$ is a useful tool for measuring mobility disability in epidemiological studies. ${ }^{27}$ Hence, we used this subscale in our study. To illustrate the magnitude of the relationship between maltreatment and physical functioning, we examined two secondary outcomes, mental health and self-rated health, for which associations with maltreatment are more established. ${ }^{82-30}$ The physical functioning and mental health subscales of the SF-36 have been shown to be relatively distinct, ${ }^{24}{ }^{25}$ while self-rated health was included to reflect a broader measure of overall health. Neglect and (different types of) abuse were examined separately (to assess whether there were differential effects on the outcomes) and combined (to assess cumulative burden). We explored to what extent associations between maltreatment and physical functioning were explained by potential intermediary factors including education level, adult smoking, mental health or socioeconomic position. Finally, in respect of other childhood factors, we investigated the relationship between childhood socioeconomic position and adult outcomes in order to assess whether previously documented associations $^{5}$ are independent of maltreatment.

\section{METHODS}

The 1958 British Birth Cohort study includes all children born in England, Scotland and Wales during 1 week in March $1958(n=17638)$ and 920 immigrants with the same birth week recruited up to age 16 years. ${ }^{31}$ Information was collected throughout childhood (birth, 7, 11 and 16years) and adulthood (23, 33, 42, 45 and 50 years) from individuals, as well as parents, teachers and school doctors (childhood surveys) and nurses (45years). Of 12252 invited, 9790 (80\%) participated in the 50-year survey (see online supplementary figure S1). Respondents in mid-adulthood were broadly representative of the surviving cohort. ${ }^{32}$ At 45 years, ethical approval was given by the South-East Multi-centre Research Ethics Committee (MREC ref 01/1/44) and at 50 years, by the London MREC (ref 08/H0718/29). Informed consent was obtained from participants at various sweeps: for example, at 45 years, respondents were given an information booklet before they agreed to participate: they were reassured on the confidentiality of their responses and reminded that they could choose not to answer questions. Respondents gave consent for their information to be deposited at the UK Data Archive and used anonymously for research purposes. Data analysts agreed to comply with the Data Archive's 'terms of use'.

\section{Childhood neglect and abuse}

Neglect was identified at 7 and 11 years from structured interviews with the child's mother (or father if the mother was unavailable) and from questionnaires completed by their teacher. Eleven indicators of neglect were selected to represent conventional definitions (table 1). Indicators were summed to create a score (range 0-11); those scoring $\geq 3$ were classified as neglected $(9.6 \%)$, in keeping with other prevalence estimates in the UK. ${ }^{816}$

Physical, psychological, witnessing and sexual abuse to age 16 years were ascertained at 45 years using a confidential Computer-Assisted Self Interviewing questionnaire (table 1). The questionnaire was originally used in the Path Through Life Project, ${ }^{33}$ details of which are described elsewhere. ${ }^{9}$

The number of types of maltreatment was summed to create a maltreatment score (range: 0-5) including neglect, physical, psychological, witnessing and sexual abuse.

\section{Adult outcomes}

Physical functioning and mental health

Physical functioning and mental health were assessed using the physical functioning and mental health subscales of the SF-36 survey, ${ }^{26}$ which was administered to participants at 50 years by postal questionnaire.

The physical functioning subscale is a validated 10-item questionnaire measuring the extent to which individuals feel that they are limited in physical activities due to their health. ${ }^{263435}$ The scale covers a range of severe and minor limitations, including lifting, carrying groceries, climbing stairs, bending, kneeling, stooping and walking 
Table 1 Definition of child maltreatment and representative variables from the 1958 British birth cohort

\begin{tabular}{|c|c|c|c|}
\hline & Definition* & 1958 cohort variables & $\begin{array}{l}\text { Age of } \\
\text { ascertainment } \\
\text { (methodf) }\end{array}$ \\
\hline \multirow{4}{*}{$\begin{array}{l}\text { Neglect } \\
\text { (7 years and } 11 \\
\text { years) }\end{array}$} & \multirow{4}{*}{$\begin{array}{l}\text { Failure to meet a child's basic } \\
\text { physical, emotional, medical/dental } \\
\text { or education need; failure to provide } \\
\text { adequate nutrition, hygiene or } \\
\text { shelter; or failure to ensure a child's } \\
\text { safety }\end{array}$} & Mother never, or hardly ever takes child out§ & 7 and 11 years $(P)$ \\
\hline & & Father never, or hardly ever takes child out§ & 7 and 11 years $(P)$ \\
\hline & & $\begin{array}{l}\text { Father shows little or no interest in child's } \\
\text { educational progress }\end{array}$ & 7 and 11 years $(T)$ \\
\hline & & $\begin{array}{l}\text { Mother and father never, or hardly ever read to, or } \\
\text { reads with the child }\end{array}$ & 7 years $(P)$ \\
\hline $\begin{array}{l}\text { Physical abuse } \\
\text { (0-16 years) }\end{array}$ & $\begin{array}{l}\text { Intentional use of physical force } \\
\text { or implements against a child that } \\
\text { results in, or has the potential to } \\
\text { result in, physical injury }\end{array}$ & $\begin{array}{l}\text { I was physically abused by a parent-punched, } \\
\text { kicked or hit or beaten with an object, or needed } \\
\text { medical treatment }\end{array}$ & 45 years $(S)$ \\
\hline \multirow{3}{*}{$\begin{array}{l}\text { Psychological } \\
\text { abuse } \\
\text { (0-16 years) }\end{array}$} & \multirow{3}{*}{$\begin{array}{l}\text { Intentional behaviour that conveys } \\
\text { to a child that she/he is worthless, } \\
\text { flawed, unloved, unwanted, } \\
\text { endangered or valued only in } \\
\text { meeting another's needs. } \\
\text { UK definition†† includes harmful } \\
\text { (unintentional) parent-child } \\
\text { interactions: 'the persistent } \\
\text { emotional maltreatment of a child } \\
\text { such as to cause severe and } \\
\text { persistent adverse effects on the } \\
\text { child's emotional development' }\end{array}$} & $\begin{array}{l}\text { I was verbally abused by a parent (or parent- } \\
\text { figure) } ी\end{array}$ & 45 years $(\mathrm{S})$ \\
\hline & & $\begin{array}{l}\text { I suffered humiliation, ridicule, bullying or mental } \\
\text { cruelty from a parent (or parent-figure) } \emptyset\end{array}$ & 45 years $(S)$ \\
\hline & & $\begin{array}{l}\text { Mother (or mother-figure) and father (or father- } \\
\text { figure) were not at all affectionate }\end{array}$ & 45 years $(S)$ \\
\hline $\begin{array}{l}\text { Sexual abuse } \\
\text { (0-16 years) }\end{array}$ & $\begin{array}{l}\text { Any completed or attempted sexual } \\
\text { act, sexual contact or non-contact } \\
\text { sexual interaction with a child by a } \\
\text { caregiver }\end{array}$ & $\begin{array}{l}\text { I was sexually abused by a parent (or parent- } \\
\text { figure) } \emptyset\end{array}$ & 45 years $(S)$ \\
\hline \multicolumn{2}{|l|}{$\begin{array}{l}\text { Childhood } \\
\text { socioeconomic } \\
\text { position }\end{array}$} & $\begin{array}{l}\text { Based on father's occupation at birth, using the } \\
\text { Registrar General's Classification, grouped in four } \\
\text { categories: (1) professional/managerial, (2) skilled } \\
\text { non-manual, (3) skilled manual and (4) partly } \\
\text { skilled/unskilled/nomale headł‡ }\end{array}$ & Birth (P) \\
\hline
\end{tabular}

${ }^{*}$ Gilbert et al, ${ }^{8}$

$\dagger(\mathrm{S})$ : self-report; $(\mathrm{T})$ : teacher-report; $(\mathrm{P})$ : parent-report.

†ltem within the Bristol Social Adjustment Guide. ${ }^{57}$

$\S$ For example, walks, outings, picnics, visits, shopping.

ๆYes /no response.

${ }^{\star *}$ Defined as a positive response to either question.

††Department for Education. ${ }^{58}$

¥\$Socioeconomic position was imputed for fathers who were unemployed or sick.

moderate distances. Participants were asked to respond on a three-point Likert scale (limited 'a lot' $=1$, 'a little' $=2$, 'not at all'=3); scores were summed and then linearly transformed to a scale ranging from 0 to 100 , with lower scores representing poorer physical functioning. A cut-off of $\leq 65$ was used to define poor physical functioning.

The mental health subscale (also known as the Mental Health Inventory-5) is a validated five-item screening 
Table 2 Prevalence of childhood maltreatment, adult physical functioning, mental health and self-rated health in the 1958 birth cohort (3997 males; 4153 females)

\begin{tabular}{lrrrr}
\hline & & All & Males Females \\
\cline { 3 - 5 } & $\mathbf{n}$ & $\%$ & $\%$ & $\%$ \\
\hline Child maltreatment 0-16 years & & & \\
\hline \multicolumn{1}{c}{ Neglect } & $7442^{*}$ & 9.6 & 10.1 & 9.0 \\
\hline Physical abuse & 8150 & 5.6 & 5.7 & 5.4 \\
\hline Psychological abuse & 8150 & 10.4 & 8.6 & 12.2 \\
\hline Witness abuse & 8150 & 5.7 & 4.2 & 7.2 \\
\hline Sexual abuse & 8150 & 1.4 & 0.5 & 2.7 \\
\hline No. of maltreatment types十 & & & & \\
\hline 0 & 4751 & 78.0 & 79.0 & 77.0 \\
\hline 1 & 930 & 15.3 & 15.3 & 15.2 \\
\hline 2 & 243 & 4.0 & 3.5 & 4.5 \\
\hline 3-5 & 164 & 2.7 & 2.2 & 3.2 \\
\hline Adult health outcomes 50 years & & & \\
\hline Poor physical functioning & 7356 & 12.0 & 9.7 & 14.5 \\
\hline Poor mental health & 7385 & 12.4 & 10.5 & 14.1 \\
\hline Poor self-rated health & 8143 & 16.9 & 16.4 & 17.5 \\
\hline
\end{tabular}

$\mathrm{N}$ varies due to missing data (based on non-imputed data). *Those complete on $\geq 6$ of 11 neglect items. †Includes neglect, physical, psychological, witnessing, sexual abuse.

questionnaire for mood and anxiety disorders. ${ }^{24}$ 36-38 Participants were asked how much of the time over the past month ('all' $=1$, 'most' $=2$, ' $\operatorname{good}$ bit' $=3$, 'some' $=4$, 'little' $=5$, or 'none' $=6$ ) they had (1) 'been a very nervous person?'; (2) 'felt calm and peaceful?'; (3) 'felt downhearted and low?'; (4) 'been a happy person'; (5) 'felt so down in the dumps that nothing cheers you up?'. Scores were reverse coded where appropriate, summed and linearly transformed to a scale ranging from 0 to 100 , with lower scores representing poorer mental health. ${ }^{24}$ As in previous studies, ${ }^{39-41}$ a cut-off of $\leq 52$ was used to identify 'poor mental health', which had been shown to best satisfy clinical diagnostic criteria for depression. ${ }^{37}$

\section{Self-rated health}

Self-rated health was ascertained during interviews at ages 23, 33, 42 and 50 years. Participants were asked to give an overall assessment of their general health on a four-point scale at 23-42years ('excellent', 'good', 'fair' or 'poor') and a five-point scale at 50 years ('excellent', 'very good', 'good', 'fair' or 'poor'). Less than 5\% of participants rated their health as 'poor' prior to 50 years; therefore, consistent with others ${ }^{28}{ }^{29}$ we define 'poor' as those with a 'poor' or 'fair' rating, hereafter referred to as 'poor' self-rated health.

While the physical functioning and mental health subscales of the SF-36 are two relatively distinct components, ${ }^{24}{ }^{25}$ self-rated health represents a broader measure which captures aspects of both physical and mental health. ${ }^{24} 42$

\section{Covariates}

Covariates were identified a priori as early-life factors associated with the outcomes. ${ }^{5-7}$ These were all prospectively measured: childhood socioeconomic position (father's occupation, as in table 1), birth weight (adjusted for gestational age), birth order (1, 2, 3, 4+), 7-year household amenities (sharing or lack of a bathroom, lavatory or hot water), 7-year household crowding ( $\geq 1.5$ people/ room), 7-year housing tenure (owner/occupier, renter or other), parental education at birth (both mother and father left school at the minimum leaving age), 7-year childhood physical or cognitive impairment (yes/no), parental chronic illness at 11 years (yes/no) and parental psychiatric illness at 11 years (yes/no). All factors were assessed using parental report, except for birth weight which was ascertained from clinical records.

\section{Potential intermediary factors}

Potential intermediary factors have been reported to be associated with both child maltreatment and adult physical functioning, including 23-year smoking ${ }^{811}$ (never, ex, light/moderate, heavy), 23-year psychological distress ${ }^{814}{ }^{41}$ (score $0-15$, assessed using the malaise inventory $^{43}$ ), 33-year educational attainment ${ }^{815}$ (no qualifications, CSE/O-level, A-level, degree level or higher) and 33-year socioeconomic position ${ }^{5}{ }^{9}$ (professional/ managerial, skilled non-manual, skilled manual and partly skilled/unskilled).

\section{ANALYSIS}

Logistic regression was used to assess associations between each child maltreatment and physical functioning, mental health and self-rated health at 50 years. For each outcome, we tested interactions between each type of maltreatment and sex; there was little evidence of effect modification; hence, results are presented for sexes combined.

We examined associations with three levels of adjustment. First, we adjusted for sex (model 1). Second, to assess whether associations were independent of other early-life factors, we additionally adjusted for covariates listed above (model 2). Third, because different types of maltreatment often co-occur, ${ }^{44}$ we mutually adjusted for all types of maltreatment simultaneously (model 3 ). In supplementary analyses, we examined whether associations were robust in a series of models restricted to weakly correlated maltreatments (pairwise correlation coefficients, $r \leq 0.2$ ). To establish whether associations between child maltreatment and self-rated health were evident at younger ages, we repeated the above analyses for all available ages. We examined the cumulative burden of multiple types of maltreatment by assessing associations between number of maltreatment types $(0,1,2, \geq 3)$ and each outcome. To assess the role of potential intermediary factors (smoking, mental health, education and 
Table 3 Associations between child maltreatment and poor physical functioning, mental health and self-rated health at 50 years

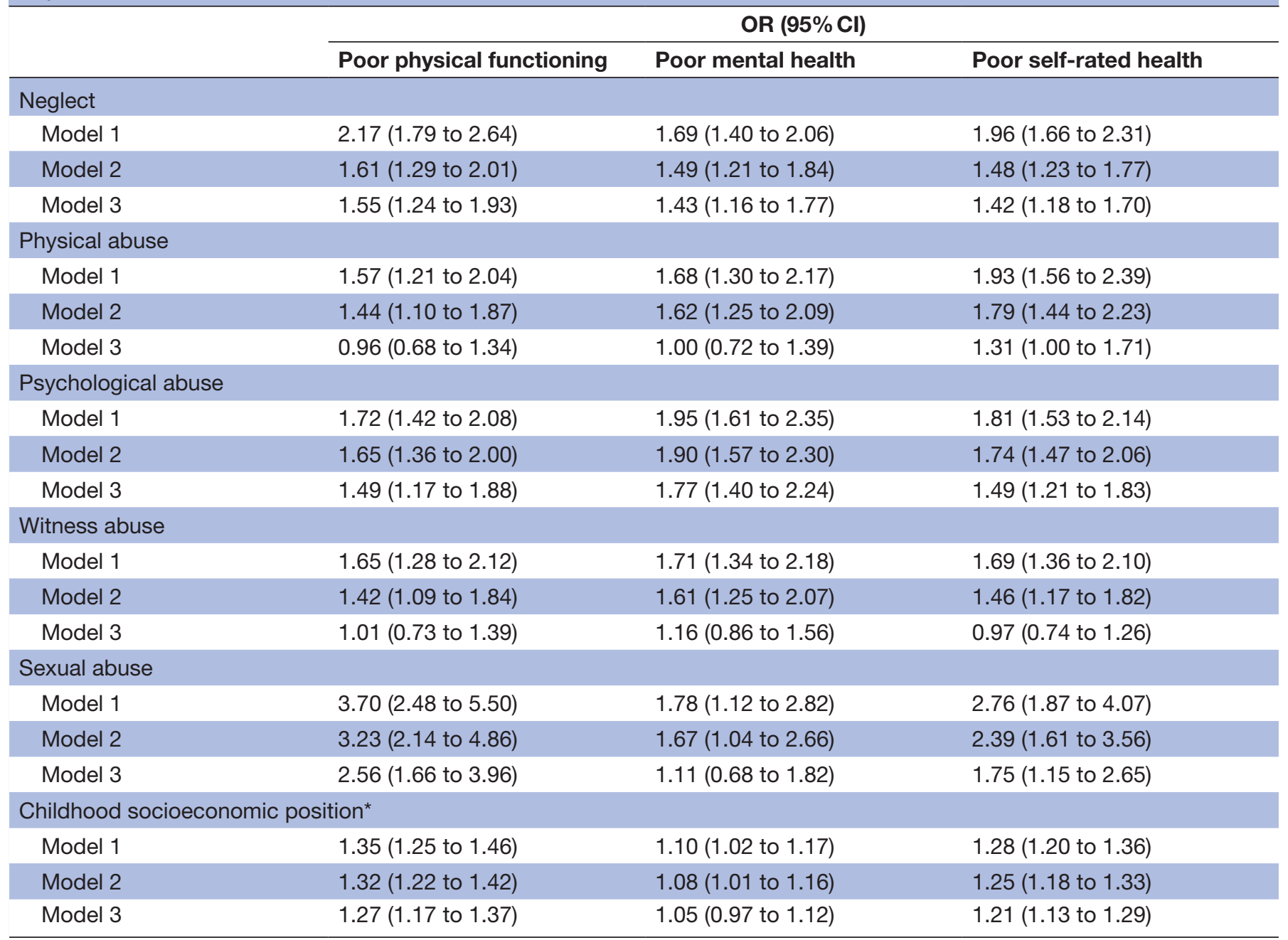

Based on 20 imputations, $\mathrm{N}=8150$.

Model 1 adjusted for sex.

Model 2 adjusted for sex and child socioeconomic position, household amenities, crowding and tenure, birth weight, birth order, child physical and cognitive impairment, parental education, parental chronic illness and parental psychiatric illness (except for childhood socioeconomic position exposure: household amenities, crowding and tenure, and parental education were excluded).

Model 3: model 2 adjustments and simultaneous adjustment for other types of maltreatment.

*Per increase across the four categories, from class I/II to IV/V.

adult socioeconomic position) in explaining associations between maltreatment and physical functioning, we further adjusted model 3 for each factor in turn. Where appropriate, the above analyses were repeated to assess associations between childhood socioeconomic position and adult outcomes, adjusting for other factors in childhood and potential intermediary factors in adulthood.

Sensitivity analyses were conducted first to test whether results were affected by single parent families; we found that excluding single parent families $(5.2 \%)$ did not alter associations of interest; thus, results are presented using the full sample. Second, to examine whether associations were robust to choice of cut-off for neglect, we repeated analyses using a more stringent cut-point $(\geq 4,6.4 \%)$. Results confirm associations presented, although with larger ORs for physical functioning and mental health, less so for self-rated health (data not shown).
Eligible participants included all those who participated in the study at 50 years and who also completed the child maltreatment questionnaire at age 45 years $(n=8150$; see online supplementary figure S1). To minimise data loss, multiple imputation using chained equations ${ }^{45}$ was used to impute missing data on indicators of neglect (range: $6.4 \%-17.8 \%$; $91.1 \%$ of participants had complete data on $\geq 6$ items), physical functioning $(9.7 \%)$, mental health $(9.4 \%)$, self-reported health $(0.1 \%)$ and all covariates (range: $2.9 \%-15.2 \%$ ). Imputation models included all study variables in addition to variables which have been identified as predicting non-response in the cohort (internalising and externalising behaviours, and cognition at 7 years). ${ }^{32}$ Analyses were run across 20 imputed datasets; imputed results were similar to those using observed values so only the former are presented. All analyses were carried out in STATA V.13.1. 
Table 4 Associations $(\mathrm{OR}, 95 \% \mathrm{Cl})$ between child maltreatment and poor physical functioning at 50 years, adjusted for adult (23years) smoking, psychological distress and education level achieved by 33 years

\section{OR $(95 \% \mathrm{Cl})$}

Poor physical functioning

\begin{tabular}{|c|c|c|c|c|}
\hline & Neglect & Psychological abuse & Sexual abuse & $\begin{array}{l}\text { Childhood } \\
\text { socioeconomic position* }\end{array}$ \\
\hline Model 3 & 1.55 (1.24 to 1.93$)$ & 1.49 (1.17 to 1.88$)$ & 2.56 (1.66 to 3.96$)$ & 1.27 (1.17 to 1.37$)$ \\
\hline +23-year smoking & 1.47 (1.17 to 1.84$)$ & 1.41 (1.15 to 1.73$)$ & 2.53 (1.65 to 3.87 ) & 1.25 (1.15 to 1.35$)$ \\
\hline $\begin{array}{l}\text { +23-year psychological } \\
\text { distress }\end{array}$ & 1.39 (1.11 to 1.74$)$ & 1.27 (1.03 to 1.56$)$ & 2.48 (1.60 to 3.82 ) & 1.24 (1.15 to 1.34$)$ \\
\hline +33-year education & $1.29(1.02$ to 1.61$)$ & $1.50(1.22$ to 1.84$)$ & 2.41 (1.58 to 3.69$)$ & 1.15 (1.06 to 1.24$)$ \\
\hline $\begin{array}{l}\text { +33-year socioeconomic } \\
\text { position }\end{array}$ & 1.40 (1.12 to 1.76$)$ & 1.53 (1.20 to 1.94$)$ & 2.36 (1.52 to 3.66$)$ & 1.20 (1.11 to 1.30$)$ \\
\hline
\end{tabular}

Based on 20 imputations, $\mathrm{n}=8150$.

Models adjusted for each intermediary factor separately (not simultaneously).

Model 3 adjusted for sex, child socioeconomic position, household amenities, crowding and tenure, birth weight, birth order, child physical and cognitive impairment, parental education, parental chronic illness and parental psychiatric illness, and simultaneously for all other types of maltreatment (except for childhood socioeconomic position exposure: household amenities, crowding and tenure, and parental education were excluded).

*Per increase across the four categories, from class I/II to IV/V.

\section{RESULTS}

Child maltreatment varied from $1.4 \%$ (sexual abuse) to $10.4 \%$ (psychological abuse); $15 \%$ experienced one type of maltreatment and $3 \%$ experienced $\geq 3$ (table 2 ). Characteristics of the included sample are shown in online supplementary table S1. The prevalence of those classified as having poor physical functioning and poor mental health were similar $(12.0 \%$ and $12.4 \%$, respectively), while $16.9 \%$ had poor self-reported health. Of those with poor physical functioning, $50 \%$ reported that they were 'limited a lot' bending, kneeling or stooping; $36 \%$ carrying groceries; and 29\% walking 100 yards (data not shown).

Physical functioning and mental health scores were weakly correlated $(r=0.28)$; only $28 \%$ of those with poor physical functioning reported poor mental health. Selfrated health was moderately correlated with physical functioning $(\mathrm{r}=0.50)$ and with mental health $(\mathrm{r}=0.36)$. Of those with poor-rated health, $46 \%$ had poor physical functioning and $33 \%$ reported poor mental health.

Table 3 shows that in sex adjusted models (model 1), all types of maltreatment were associated with poor physical functioning at 50 years. Associations attenuated but remained after adjustment for covariates, with ORs ranging from 1.42 (95\% CI 1.09 to 1.84$)$ to 3.23 (2.14 to 4.86 ) for witness and sexual abuse, respectively (model 2$)$. When all maltreatment types were considered simultaneously, associations remained for neglect, psychological and sexual abuse, although ORs reduced to 1.55 (1.24 to 1.93), 1.49 (1.17 to 1.88 ) and 2.56 (1.66 to 3.96$)$, respectively, whereas associations for physical and witnessing abuse were completely attenuated (model 3). Results were similar to those reported here when we examined associations in models restricted to the least correlated maltreatments (see online supplementary table S2). Except for sexual abuse, maltreatment associations were generally of similar magnitude for mental health and self-rated health at 50 years (tables 3 and 4 ). For example, ORs for neglect were 1.55 (1.24 to 1.93$), 1.43$ (1.16 to 1.77 ) and 1.42 (1.18 to 1.70 ) for poor physical functioning, mental health and self-rated health, respectively (table 3, model 3).

For childhood socioeconomic position, the $\mathrm{OR}_{\mathrm{adj}}$ of poor physical functioning was 1.27 (1.17 to 1.37) per decrease on the four-point scale (table 3, model 3); comparing the lowest class (IV/V) with highest (I/II) class, the $\mathrm{OR}_{\text {adj }}$ for poor physical functioning was 2.03 (ie, $\left.1.27^{3}\right)(1.56$ to 2.50$)$. Similar associations were observed for self-rated health; however, childhood socioeconomic position was not associated with mental health in model 3.

Associations between maltreatment and physical functioning were only partially attenuated by potential intermediary factors (table 4$)$. The $\mathrm{OR}_{\text {adj }}$ for neglect reduced from 1.55 (1.24 to 1.93$)$ to 1.29 (1.02 to 1.61$)$ after adjustment for education level, with lesser attenuating effects for mental health and adult socioeconomic position. ORs for sexual abuse remained, although attenuated after adjustment for education and adult socioeconomic position (eg, from 2.56 (1.66 to 3.96) to 2.36 (1.52 to 3.66) after adjusting for the latter). In contrast, ORs for psychological abuse were attenuated only by adjustment for mental health: from 1.49 (1.17 to 1.88 ) to 1.27 (1.03 to 1.56$)$. As expected, associations between childhood socioeconomic position and physical functioning weakened after adjusting for education (1.27 (1.17 to 1.37$)$ to 1.15 (1.06 to 1.24$)$ per decrease in socioeconomic position) and to a lesser extent adult socioeconomic position.

In covariate adjusted analyses, associations between maltreatment and self-rated health at 50 years were similar in magnitude to those observed at earlier ages $(23,33$ and 42 years) (see online supplementary table S3, model 
Table 5 Associations between number of types of maltreatment and poor physical functioning, mental health and self-rated health at 50 years

\begin{tabular}{|c|c|c|c|}
\hline & \multicolumn{3}{|c|}{ OR $(95 \% \mathrm{Cl})$} \\
\hline & Poor physical functioning & Poor mental health & Poor self-rated health \\
\hline \multicolumn{4}{|l|}{ No. of types of maltreatment $†$} \\
\hline \multicolumn{4}{|l|}{ Model 1} \\
\hline 0 & Ref & Ref & Ref \\
\hline 1 & 1.82 (1.52 to 2.19$)$ & 1.79 (1.50 to 2.13$)$ & 1.77 (1.51 to 2.06$)$ \\
\hline 2 & 2.09 (1.54 to 2.85$)$ & 2.02 (1.51 to 2.70$)$ & 2.27 (1.76 to 2.94$)$ \\
\hline $3-5$ & 2.53 (1.86 to 3.43$)$ & 2.26 (1.64 to 3.11$)$ & 2.57 (1.94 to 3.40$)$ \\
\hline \multicolumn{4}{|l|}{ Model 2} \\
\hline 0 & Ref & Ref & Ref \\
\hline 1 & 1.49 (1.23 to 1.82$)$ & 1.68 (1.40 to 2.01$)$ & 1.48 (1.26 to 1.74$)$ \\
\hline 2 & 1.83 (1.34 to 2.51$)$ & 1.95 (1.45 to 2.61$)$ & 2.04 (1.57 to 2.65$)$ \\
\hline $3-5$ & 2.09 (1.53 to2.87) & 2.12 (1.53 to 2.94$)$ & 2.15 (1.62 to 2.87$)$ \\
\hline Per additional maltreatment & $1.33(1.21 \text { to } 1.45)^{\star}$ & $1.36(1.25 \text { to } 1.48)^{\star}$ & $1.35(1.26 \text { to } 1.46)^{*}$ \\
\hline
\end{tabular}

Based on 20 imputations, $\mathrm{N}=8150$.

Model 1 adjusted for sex.

Model 2 adjusted for sex and child socioeconomic position, household amenities, crowding and tenure, birth weight, birth order, child physical and cognitive impairment, parental education, parental chronic illness and parental psychiatric illness.

${ }^{*} P_{\text {trend }}<0.001$.

†Includes neglect, physical, psychological, witnessing and sexual abuse.

2); for example, $\mathrm{OR}_{\mathrm{adj}}$ for psychological abuse was 1.65 (1.29 to 2.12$)$ at age 23 , and 1.74 (1.47 to 2.06$)$ at 50 years. However, associations were less consistent after simultaneous adjustment for all maltreatments (model 3).

There was a dose-response relationship between number of types of maltreatment and poor physical functioning: covariate adjusted ORs ranged from 1.43 (1.16 to 1.77) for a single type of maltreatment to 2.09 (1.53 to 2.87) for those reporting $\geq 3$ types $\left(\mathrm{p}_{\text {trend }}<0.001\right.$; table 5).

\section{DISCUSSION}

In this large population-based study of child maltreatment and adult health outcomes, we showed several important findings. First, neglect and psychological abuse were associated with higher odds, by approximately $50 \%$ of poor physical functioning, while sexual abuse was associated with higher odds of more than twofold. Importantly, these associations were independent of other child maltreatments and covariates including early-life factors linked to physical functioning, such as socioeconomic factors, ${ }^{5}$ parental health ${ }^{7}$ and birth weight. ${ }^{646}$ Second, in regard to potential intermediary factors, our findings suggest that adult socioeconomic position is intermediate in associations for neglect and sexual abuse, while for psychological abuse, adult psychological distress is likely to be important. Third, associations between child maltreatment and physical functioning were generally of comparable magnitude to those observed for mental health and self-rated health, even though poor physical functioning and poor mental health represented largely distinct groups. Fourth, there was evidence of an accumulating burden for those experiencing multiple types of maltreatment, with those experiencing $\geq 3$ types having twice the odds of poor physical functioning compared with those experiencing none. Finally, childhood socioeconomic position was associated with adult physical functioning, independent of other early-life factors including maltreatment and also of adult socioeconomic position.

\section{METHODOLOGICAL CONSIDERATIONS}

Our study has several strengths including a long follow-up period (birth to 50 years), and prospectively measured outcomes and covariates, although the possibility of residual confounding cannot be excluded. While our outcomes were self-reported, all have been shown to predict mortality, ${ }^{2-4} 4748$ and have been validated against objective assessments of physical performance (eg, grip strength) ${ }^{35}$ medical conditions ${ }^{24} 34$ and clinical psychiatric evaluations. ${ }^{24}{ }^{38}$ Multiple types of child abuse and neglect were assessed both prospectively and retrospectively; however, as with all methods of ascertainment, ${ }^{8}$ the measures have limitations. For example, our neglect indicators cover many (eg, failure to ensure a child's basic physical or educational needs) but not all (eg, failure to ensure a child's safety) aspects of the conventional definition. ${ }^{8}$ However, use of a composite score with multiple sources of reporting (ie, parent and teacher) may help to reduce neglect misclassification ${ }^{49}$; also, we showed that our findings for neglect were robust to choice of cut-point. Retrospective reports of parental abuse provided no information on duration, timing or frequency, and also exclude 
abuse by non-parents, which could lead to an underestimate of the prevalence. ${ }^{50}$ Except for sexual abuse, where perpetrators are less likely to be parents, ${ }^{50}$ our prevalence estimates for abuse and neglect are in line with other reviews. ${ }^{81650}$ There are concerns that the validity of retrospective reports of child maltreatment could be influenced by current circumstances ${ }^{51}$; we acknowledge that we cannot rule out this possibility. However, results for self-rated health at different ages suggest that recall bias is unlikely to account for associations observed for outcomes at 50 years: that is, findings for self-rated health at 23 years (many years prior to the reporting of abuse) were generally consistent with those seen for self-rated health at 50 years. It is relevant that measures of child abuse were ascertained 5 years prior to our main outcome, and also that our previous studies have shown expected associations between retrospective reports of abuse and prospectively measured family dysfunction ${ }^{52}$ and mental health, ${ }^{41}$ suggesting good construct validity. Finally, there has been attrition in the study sample over time: although respondents in mid-adulthood were generally representative of the surviving cohort, disadvantaged groups were the most likely to be under-represented..$^{32}$ As expected, child maltreatment groups are more likely to be under-represented in our study: for example, for neglect the prevalence was $9.6 \%$ in the study sample versus $12.5 \%$ in the childhood sample. However, previous work on potential attrition bias relating to child maltreatment in this cohort suggests that effects are negligible for associations with mental health at 50 years ${ }^{41}$; even so, the possibility of such bias cannot be ruled out. For missing data, we maximised available data by including all who participated at 50 years who had data on retrospective measures of abuse and followed current guidelines on multiple imputation to avoid sample reduction due to missing data. ${ }^{53}$

\section{Interpretation and comparison with other studies}

Our findings that neglect, psychological and sexual abuse were associated with an increased odds of poor physical functioning at 50 years are largely consistent with previous cross-sectional studies from the USA ${ }^{17-21}$ which found that adverse childhood experiences, ${ }^{17-19}$ sexual $^{20} 21$ and non-sexual abuse ${ }^{20}$ were associated with poor physical functioning and disability. We make several important contributions to existing literature by showing that observed associations are independent of other early-life factors known to be associated with poor physical functioning in adulthood, such as low birth weight, ${ }^{6}{ }^{46}$ poor parental health ${ }^{7}$ and low socioeconomic position. ${ }^{5}$ Moreover, to our knowledge, our findings for neglect are novel, as all previous studies have combined neglect with other maltreatments ${ }^{19} 20$; this is noteworthy because neglect is relatively common, ${ }^{816}$ yet it is often underexamined. In respect of childhood socioeconomic position, our finding of an association with physical functioning that was independent of maltreatment (and also birth weight) suggests that early economic environment contributes to adult outcome separately from these other early-life adversities, that is, socioeconomic position is not a proxy for maltreatment and vice versa.

Previous studies have relied on mixed aged samples ${ }^{17-21}$; however, we assessed physical functioning at 50 years which is important because those with poor physical functioning at this age are likely to enter a state of disability (ie, the inability to carry out activities needed to function in society) sooner compared with those reporting no or mild limitations. ${ }^{54}$ Many $(50 \%)$ of those identified here as having poor physical functioning reported substantial limitation with bending, kneeling or stooping and about a third had limitations carrying groceries and walking a short distance (100 yards). Age 50 years is close to peak earning capacity in the $\mathrm{UK}^{55}$; thus, physical limitations at this age are likely to lead to long-term hardship due to difficulties undertaking paid employment, ${ }^{24}$ and associated ill health during old age.

There was evidence that neglect, psychological and sexual abuse were independently associated with physical functioning, but not physical or witnessing abuse, suggesting that different maltreatments may have differential effects. Explanations for the lack of association for physical and witnessing abuse are uncertain; however, due to moderate correlations between physical, witnessing and psychological abuse, these findings should be interpreted with caution. For neglect and sexual abuse, our findings relating to potential intermediary factors suggest that associations with physical functioning were partially explained by education level and adult socioeconomic position, which is consistent with our previous work showing unfavourable socioeconomic trajectories in adulthood for these groups. ${ }^{9}$ In contrast, findings for psychological abuse suggest that the association with physical functioning may be explained partly by psychological distress rather than socioeconomic factors, which is in line with previous work suggesting that depression predicts physical functioning trajectories. ${ }^{14}$ The childhood socioeconomic position association with physical functioning was most strongly attenuated by education and adult socioeconomic position; however, in contrast to other maltreatments, it was unaffected after adjustment for psychological distress. These findings suggest that different maltreatments, and social disadvantage, may have unique pathways to poor physical functioning; this provides important clues on likely child to adult mechanisms and potential intervention targets. Child sexual abuse and socioeconomic position associations with physical functioning were only partially attenuated following adjustment for smoking, psychological distress, education and adult socioeconomic position, which suggests that other unexamined factors could play an important intermediary role. Our findings confirm previous reports that associations for childhood socioeconomic position remain after allowing for adult socioeconomic position ${ }^{5}$ and they add new knowledge regarding the likely minor contributory role of adult smoking and psychological distress. Further clues on pathways from child maltreatments to poor physical functioning in adulthood may be 
gleaned in future studies of potential intermediaries such as chronic health conditions and acquired disabilities.

A novel observation from our study was that, in general, the magnitude of associations between individual maltreatments and mid-adult physical functioning was similar to those for mental health and self-rated health. This finding is important because, in contrast to mental health where the consequences of childhood maltreatment have long been recognised, possible impacts on adult physical functioning have not been fully appreciated. The magnitude of maltreatment-physical functioning associations was not negligible, and comparable to those found in the few other existing studies. ${ }^{10}{ }^{17}$ For example, across our three outcome measures, ORs varied between 1.4 and 1.6 for neglect, and 1.5 and 1.8 for psychological abuse, while other studies of non-sexual abuse reported ORs in the region of 1.3-2.4 for disability ${ }^{17}$ and 1.5-3.1 for depressive disorders. ${ }^{10}$

In contrast to previous work, ${ }^{21}$ our findings suggest that sexual abuse has larger associations with physical functioning and self-rated health compared with mental health; however, discrepancies are likely to be due to the low prevalence of sexual abuse or differences in study design. Also, we showed comparable dose-response relationships between the number of types of maltreatment and the three outcome measures, which is consistent with other studies suggesting that greater exposure to adverse childhood experiences (including maltreatment) is linked to higher levels of disability, ${ }^{17}$ depressed mood, ${ }^{29} 41$ poor self-rated health, ${ }^{29}$ long-term sickness absence ${ }^{9}$ and other health conditions. ${ }^{1029}$

Despite the similarity of magnitude of associations in our study across the three outcome measures, it is important to note that the physical functioning and mental health scales captured two relatively distinct constructs: as originally intended in the construction of the SF- 36 scales $^{34}$ and demonstrated in previous work. ${ }^{24} 42$ Consistent with this, we found weak correlations between physical functioning and mental health, suggesting that associations between child maltreatment and physical functioning and mental health are relatively distinct. As expected, physical functioning and self-rated health were moderately correlated, suggesting that there is overlay in these constructs. Our findings for self-rated health at several ages in adulthood (23 to 50years) suggest that to some extent associations between child maltreatment and self-rated health emerge in early adulthood and then persist across subsequent decades of life.

\section{Conclusions and implications}

Our study suggests that neglect, psychological and sexual abuse have long-term associations with poor physical functioning at 50 years, with accumulating burden for those experiencing multiple types of maltreatment. We contribute to the existing literature by demonstrating that associations were independent of other early-life factors linked to poor physical functioning in later life and by showing that the magnitude of associations for physical functioning was largely comparable to those for mental health and self-rated health. Importantly, those with poor physical functioning and poor mental health are relatively distinct groups. Our results suggest that maltreated children grow up with a higher risk of experiencing problems performing the physical tasks of daily living in adulthood, which is likely to affect economic productivity, and lead to increased risk of disability and poor health at older ages. It has been argued elsewhere that clinicians and others, including policymakers, need to be aware of the later chronic physical and mental health problems associated with child maltreatment, ${ }^{56}$ and our findings suggest that this also applies to physical mobility and functioning with advancing age. Unless findings such as those shown here are recognised and action taken, opportunities will be missed to prevent detrimental long-term outcomes of child maltreatments. Given the prevalence of maltreatment in the general population and its sizeable association with adult physical functioning, our findings suggest that the prevention of maltreatment and the alleviation of its ill effects could be an effective policy intervention, relevant to all countries with ageing populations.

Acknowledgements The authors are grateful to the Centre for Longitudinal Studies (CLS), UCL Institute of Education for the use of these data and to the UK Data Service for making them available. However, neither CLS nor the UK Data Service bear any responsibility for the analysis or interpretation of these data

Contributors All authors designed and conducted the research. GA performed statistical analyses and drafted the manuscript. SMPP and CP reviewed and revised the manuscript. CP had primary responsibility for final content. All authors approved the final manuscript as submitted.

Funding This research was funded by the Department of Health Policy Research Programme through the Public Health Research Consortium (PHRC) and supported by the NIHR Great Ormond Street Hospital Biomedical Research Centre. The views expressed in the publication are those of the authors and not necessarily those of the NIHR or the Department of Health. Information about the wider programme of the PHRC is available from http://phrc.Ishtm.ac.uk. The funders had no input into study design; data collection, analysis and interpretation; in the writing of the report; and in the decision to submit the article for publication. Researchers were independent of influence from study funders.

Competing interests None declared.

Ethics approval Ethical approval for the 45 year survey was given by the South-East Multi-centre Research Ethics Committee (ref 01/1/44) and for the 50y survey by the London Multi-centre Research Ethics Committee (ref 08/H0718/29); informed consent was obtained

Provenance and peer review Not commissioned; externally peer reviewed.

Data sharing statement Cohort data comply with ESRC data sharing policies, readers can access these data via the UK Data Archive at http://www.data-archive. ac.uk/

Open Access This is an Open Access article distributed in accordance with the Creative Commons Attribution Non Commercial (CC BY-NC 4.0) license, which permits others to distribute, remix, adapt, build upon this work non-commercially, and license their derivative works on different terms, provided the original work is properly cited and the use is non-commercial. See: http://creativecommons.org/ licenses/by-nc/4.0/

C Article author(s) (or their employer(s) unless otherwise stated in the text of the article) 2017. All rights reserved. No commercial use is permitted unless otherwise expressly granted.

\section{REFERENCES}

1. Government Office for Science. Future of an ageing population. 2016 www.gov.uk/go-science 
2. Brock DB, Lemke JH, Branch LG, et al. Mortality and physical functioning in epidemiologic studies of three older populations. $J$ Aging Soc Policy 1994;6:21-37.

3. Guralnik JM, Simonsick EM, Ferrucci L, et al. A short physical performance battery assessing lower extremity function: association with self-reported disability and prediction of mortality and nursing home admission. J Gerontol 1994;49:M85-94.

4. Cooper R, Kuh D, Hardy R, et al. Objectively measured physical capability levels and mortality: systematic review and meta-analysis. BMJ 2010;341:c4467.

5. Birnie K, Cooper R, Martin RM, et al. Childhood socioeconomic position and objectively measured physical capability levels in adulthood: a systematic review and meta-analysis. PLoS One 2011;6:e15564.

6. Kuh D, Hardy R, Butterworth S, et al. Developmental origins of midlife grip strength: findings from a birth cohort study. J Gerontol A Biol Sci Med Sci 2006;61:702-6.

7. Mishra GD, Black S, Stafford M, et al. Childhood and maternal effects on physical health related quality of life five decades later: the British 1946 birth cohort. PLoS One 2014;9:e88524.

8. Gilbert R, Widom CS, Browne K, et al. Burden and consequences of child maltreatment in high-income countries. Lancet 2009;373:68-81.

9. Pinto Pereira SM, Li L, Power C. Child maltreatment and adult living standards at 50 years. Pediatrics 2017;139:e20161595.

10. Norman RE, Byambaa M, De R, et al. The long-term health consequences of child physical abuse, emotional abuse, and neglect: a systematic review and meta-analysis. PLoS Med 2012;9:e1001349

11. Østbye T, Taylor DH, Jung SH. A longitudinal study of the effects of tobacco smoking and other modifiable risk factors on ill health in middle-aged and old Americans: results from the Health and Retirement Study and Asset and Health Dynamics among the Oldest Old survey. Prev Med 2002;34:334-45.

12. Rejeski WJ, Marsh AP, Chmelo E, et al. Obesity, intentional weight loss and physical disability in older adults. Obes Rev 2010;11:671-85.

13. Guralnik JM, LaCroix AZ, Abbott RD, et al. Maintaining mobility in late life. I. Demographic characteristics and chronic conditions. Am J Epidemiol 1993;137:845-57.

14. Rhebergen D, Beekman AT, de Graaf R, et al. Trajectories of recovery of social and physical functioning in major depression, dysthymic disorder and double depression: a 3-year follow-up. J Affect Disord 2010;124:148-56.

15. Zimmer Z, House JS. Education, income, and functional limitation transitions among American adults: contrasting onset and progression. Int J Epidemiol 2003;32:1089-97.

16. Radford L, Corral S, Bradley C, et al. Child abuse and neglect in the UK today. $2011 \mathrm{http}: / /$ clok.uclan.ac.uk/6022/ (accessed 21 Sep 2016).

17. Schüssler-Fiorenza Rose SM, Xie D, Stineman M. Adverse childhood experiences and disability in U.S. adults. $P m R$ 2014;6:670-80.

18. Edwards VJ, Anda RF, Felitti VJ, et al. Adverse childhood experiences and health-related quality of life as an adult. Kendall-Tackett $\mathrm{K}$, ed. Victimization and Health. American Psychological Association, 2004:81-94. http://psycnet.apa.org/psycinfo/2003-88342-005/. (accessed 18 Jan 2017)

19. Leserman J, Li Z, Hu YJ, et al. How multiple types of stressors impact on health. Psychosom Med 1998;60:175-81.

20. Walker EA, Gelfand A, Katon WJ, et al. Adult health status of women with histories of childhood abuse and neglect. Am J Med 1999;107:332-9.

21. Dickinson LM, deGruy FV, Dickinson WP, et al. Health-related quality of life and symptom profiles of female survivors of sexual abuse. Arch Fam Med 1999;8:35-43.

22. Kraemer HC, Wilson KA, Hayward C. Lifetime prevalence and pseudocomorbidity in psychiatric research. Arch Gen Psychiatry 2006;63:604-8.

23. World Health Organization. International Classification of Functioning, Disability, and Health. Geneva: World Health Organization, 2001.

24. Ware JE, Kosinski M, Dewey JE, et al. SF-36 health survey: manual and interpretation guide. Quality Metric Inc 2000.

25. Ware JE. SF-36 health survey update. Spine 2000;25:3130-9.

26. Ware JE, Sherbourne CD. The MOS 36 -item short-form health survey (SF-36). I. Conceptual framework and item selection. Med Care 1992;30:473-83.

27. Syddall HE, Martin HJ, Harwood RH, et al. The SF-36: a simple, effective measure of mobility-disability for epidemiological studies. $J$ Nutr Health Aging 2009;13:57-62.

28. Boynton-Jarrett R, Ryan LM, Berkman LF, et al. Cumulative violence exposure and self-rated health: longitudinal study of adolescents in the United States. Pediatrics 2008;122:961-70.
29. Felitti VJ, Anda RF, Nordenberg D, et al. Relationship of childhood abuse and household dysfunction to many of the leading causes of death in adults. The Adverse Childhood Experiences (ACE) Study. Am J Prev Med 1998;14:245-58.

30. Mersky JP, Topitzes J, Reynolds AJ. Impacts of adverse childhood experiences on health, mental health, and substance use in early adulthood: a cohort study of an urban, minority sample in the U.S. Child Abuse Negl 2013;37:917-25.

31. Power C, Elliott J. Cohort profile: 1958 British birth cohort (National Child Development Study). Int J Epidemiol 2006;35:34-41.

32. Atherton K, Fuller E, Shepherd P, et al. Loss and representativeness in a biomedical survey at age 45 years: 1958 British birth cohort. $J$ Epidemiol Community Health 2008;62:216-23.

33. Rosenman S, Rodgers B. Childhood adversity in an Australian population. Soc Psychiatry Psychiatr Epidemiol 2004;39:695-702.

34. McHorney CA, Ware JE, Lu JF, et al. The MOS 36-item Short-Form Health Survey (SF-36): III. Tests of data quality, scaling assumptions, and reliability across diverse patient groups. Med Care 1994;32:40-66.

35. Syddall HE, Martin HJ, Harwood RH, et al. The SF-36: a simple, effective measure of mobility-disability for epidemiological studies. $J$ Nutr Health Aging 2009;13:57-62.

36. Berwick DM, Murphy JM, Goldman PA, et al. Performance of a fiveitem mental health screening test. Med Care 1991;29:169-76.

37. Holmes WC. A short, psychiatric, case-finding measure for HIV seropositive outpatients: performance characteristics of the 5 -item mental health subscale of the SF-20 in a male, seropositive sample. Med Care 1998;36:237-43.

38. Rumpf HJ, Meyer C, Hapke U, et al. Screening for mental health: validity of the MHI-5 using DSM-IV Axis I psychiatric disorders as gold standard. Psychiatry Res 2001;105:243-53.

39. Maddock J, Berry DJ, Geoffroy MC, et al. Vitamin D and common mental disorders in mid-life: cross-sectional and prospective findings. Clin Nutr 2013;32:758-64.

40. Pan A, Lucas $M$, Sun $Q$, et al. Increased mortality risk in women with depression and diabetes mellitus. Arch Gen Psychiatry 2011;68:42-50

41. Geoffroy MC, Pinto Pereira S, Li L, et al. Child neglect and maltreatment and childhood-to-adulthood cognition and mental health in a prospective birth cohort. J Am Acad Child Adolesc Psychiatry 2016;55:33-40.

42. Mavaddat N, Kinmonth AL, Sanderson S, et al. What determines Self-Rated Health (SRH)? A cross-sectional study of SF-36 health domains in the EPIC-Norfolk cohort. J Epidemiol Community Health 2011;65:800-6.

43. Geoffroy MC, Hertzman C, Li L, et al. Prospective association of morning salivary cortisol with depressive symptoms in mid-life: a lifecourse study. PLoS One 2013;8:e77603.

44. Dong M, Anda RF, Felitti VJ, et al. The interrelatedness of multiple forms of childhood abuse, neglect, and household dysfunction. Child Abuse Negl 2004;28:771-84.

45. Little RJ, Rubin DB. Statistical analysis with missing data: John Wiley \& Sons, 2014. https://books.google.co.uk/books?hl=en\&lr=\&id= AyVeBAAAQBAJ\&oi=fnd\&pg=PT8\&dq=Statistical+Analysis+with+ Missing+Data\&ots $=$ uxW_aDkQaB\&sig=YTMbgpY3vbITuXxNa4xZ4ajbFE. (accessed 19 Oct 2016).

46. Kuh D, Bassey J, Hardy R, et al. Birth weight, childhood size, and muscle strength in adult life: evidence from a birth cohort study. Am J Epidemiol 2002;156:627-33.

47. Idler EL, Benyamini Y. Self-rated health and mortality: a review of twenty-seven community studies. J Health Soc Behav 1997;38:21-37.

48. Wulsin LR, Vaillant GE, Wells VE. A systematic review of the mortality of depression. Psychosom Med 1999;61:6-17.

49. Kendall-Tackett K, Becker-Blease K. The importance of retrospective findings in child maltreatment research. Child Abuse Negl 2004;28:723-7.

50. Office for National Statistics. Abuse during childhood: Findings from the Crime Survey for England and Wales, year ending March 2016, 2016. https://www.ons.gov.uk/peoplepopulationandc ommunity/crimeandjustice/articles/abuseduringchildhood/finding sfromtheyearendingmarch2016crimesurveyforenglandandwales.

51. Widom CS, Raphael KG, DuMont KA. The case for prospective longitudinal studies in child maltreatment research: commentary on Dube, Williamson, Thompson, Felitti, and Anda (2004). Child Abuse Negl 2004;28:715-22.

52. Denholm R, Power C, Thomas C, et al. Child Maltreatment and Household Dysfunction in a British Birth Cohort. Child Abuse Rev 2013;22:340-53.

53. Sterne JA, White IR, Carlin JB, et al. Multiple imputation for missing data in epidemiological and clinical research: potential and pitfalls. BMJ 2009;338:b2393. 
54. Peeters G, Dobson AJ, Deeg DJ, et al. A life-course perspective on physical functioning in women. Bull World Health Organ 2013;91:661-70.

55. Office for National Statistics. Annual Survey of Household Earnings 2015, Provisional results, 2015.

56. Springer KW, Sheridan J, Kuo D, et al. The long-term health outcomes of childhood abuse. J Gen Intern Med 2003;18:864-70.
57. Stott D. The Social-Adjustment of Children: Manual to the Bristol Social-Adjustment Guides. London: University of London Press, 1963.

58. Department for Education. Working together to safeguard children 2016 https://www.gov.uk/government/uploads/system/uploads/ attachment_data/file/419595/Working_Together_to_Safeguard Children.pdf (accessed 17 Nov 2016). 